\title{
Evaluating the impact of information systems on end user performance: A proposed model
}

\author{
Ahed Abugabah, Louis Sanzogni, and Osama Alfarraj \\ Griffith University, Brisbane, Australia \\ a.abugabah, L.sanizo, o.alfarraj@griffith.edu.au
}

\begin{abstract}
In the last decades, information systems (IS) researchers have concentrated their efforts in developing and testing models that help with the investigation of IS and user performance in different environments. As a result, a number of models for studying end users' systems utilization and other related issues including system usefulness, system success and user aspects in business organizations have appeared. A synthesized model consolidating three well-known and widely used models in IS research is proposed.

Our model was empirically tested in a sophisticated IS environment investigating the impacts of the enterprise recourse planning (ERP) systems on user perceived performance. Statistical analysis was performed including factors analysis and regression to test the model and prove its validity. The findings demonstrated that the proposed model performed well as most factors had direct and or indirect significant influences on user perceived performance suggesting therefore that the model possesses the ability to explain the main impacts of these factors on ERP users.
\end{abstract}

Keywords: Information systems, user performance, task technology fit, technology acceptance model.

\section{INTRODUCTION}

From the mid-nineties, IS researchers have concentrated their research efforts in developing and testing models that help in investigating IS aspects in different environments. As a result, a number of models for studying the systems utilization of end users and other related issues including system use, system success and user aspects in business organizations appeared.

The most commonly used models are, the technology acceptance model (TAM), the tasktechnology fit model (TTF), and DeLone and McLean (D\&M) model. Each model focuses on different aspects and has different perspectives on the impacts of IS on users and or at least follows a specific researcher's goals and purposes. Overall, previous models provide a much-needed theoretical basis for exploring the factors that explain IS utilization and impacts on user performance [16].

This signifies the need for a model that can help understand the relationship between IS and users in different environments. Such a model should encompass different dimensions of IS, technology and users contemporaneously. This would help identify most overall important aspects and shift the focus from less important factors to more important factors that bring new useful ideas to both practitioners and researchers.

This study thus starts with a common argument that the aforementioned models were criticized for different reasons as each one alone tells only a particular part of the story and none of them alone has achieved a universal acceptance in terms of comprehensiveness and suitability to various IS environments. The study also discusses weaknesses among these models and the overlap between them as a basic step to understand a suitable way to integrating them into one more comprehensive and powerful model. For example, we note that the development of new and complex IS, such as ERP systems require different investigative approaches.

\section{LITERATURE REVIEW}

The difficulty in measuring actual performance led many previous studies to use multiple perspectives and theories to reach more accurate and rigorous results [39], [1]. Thus, we argue that current IS models individually are not broad enough to measure such a relationship as they do only capture a subset of the factors in the broad context of IS, reflecting a common agreement between many researchers [29], [16], [21]. For example, TAM and TTF overlap in a significant way and they could provide a more coherent model if they are integrated, such that model could be even stronger than either standing alone. Recent research on the D \& M's model also showed that the model is incomplete and needs to be extended with other factors [29], such as usefulness and the importance of the systems [34].

In light of these facts, especially the difficulty of objectively measuring performance, IS researchers have used these models as surrogate measures to predict users behaviours and IS successes in various types of IS environments and business organizations [35]. For that reason, research on extending, integrating and replicating these models and constructs has been appearing in the IS literature [18], [32]. 
There are many examples of this, for instance, [32] developed a new model by integrating the user satisfaction model with other variables such as information accuracy, system adequacy and timeliness to investigate user satisfaction in small business. In another instance, [39] extended TAM in order to investigate the actual usage of the systems. [17], integrated TAM and TTF to investigate individual performance because the new model has more significant improvement over either model alone. The integrated model provided more explanatory power than any of these models alone. Later on [18], also proposed a model extending TTF with a computer self-efficacy construct explaining the link between the two models to help managers understand PEOU can be increased.

In a similar vein, [27] extended TAM and TTF in on an internet environment and found support for a model that includes TTF and the TAM to predict actual use and attention to use, others also extended TAM with other variables from IS literature and found support for integrating new variables to new models in different environments [5], [2], [7].

Recently, researchers have started even to expand these models with new factors aiming at developing new models to suit with the advanced and complex IS projects in various industries [23], [26]. [38], used an extended model to study the relationship between TAM variables and actual usage. [41], demonstrated that the extended TAM with initiative IT factors such as facility and compatibility the model possesses the ability to interpret individual behaviour and users' acceptance.

Prior IS models including TAM and TTF were used to carried out research in traditional and relatively simple but important environments, such as spreadsheet software and personal computing [2]. However, with the development and implementation of complex and costly IS that cut across organizational functions, it is clear that there is an increased need for research that examines these models and extends them to a complex IS environment [24].

Despite the large body of existing research on TAM, TTF and D \& M's models [21], [28], [20], none of these models have achieved universal acceptance either due to narrowness of focus or inadequately developed methodologies [10]. These largely independent streams of research sparked our interest to explicitly discuss the main weakness in previous models with the goal of combining a new powerful validated model to further the understanding of the relationship between IS and users including performance impacts and systems usefulness [22], [13], [14]. Previous models focused on user acceptance and satisfaction as surrogates to measure the impact of IS on individual user's performance [15], [33], [29]. The argument in support of this approach stems from the difficulty in identifying a set of objective measures to evaluate the benefits of IS to users and organizations [3].

Specifically, a number of important shortcomings plague these models. For instance, TAM is widely employed in IS research, but has been criticized because of lack of task concentration [16], inability to address how other variables affect core TAM variables, such as usefulness [2], over assumptions on voluntary system utilization [22], some explicit recognition that frequent utilization of a system may not lead to higher user's performance and inadequate systems may be evaluated positively by users due to factors such as accessibility, and personal characteristics [22].

Similarly, a major concern about studies conducted using TTF is the inadequate attention given to a very important element related to system quality and usefulness especially when it is known that system usefulness must be evaluated before systems can deliver performance impacts [22].

The D \& M's model is one of the most widely applied in IS research. It identifies the complexity that surrounds the definition of IS success offering valuable contributions to the understanding of IS performance impacts and providing a scheme for classifying the different measures of IS. However, researchers have claimed that the D \& M's model is incomplete; suggesting that further factors should be included in the model [12], [40], [38], [29].

In view of that, this study developed and statistically validated a new model for examining the impact of IS on user performance. The model combines the core factors from the TAM, TTF and D \& M's models (See figure 1 below), thereby achieving a more adequate and accurate measure of user performance.

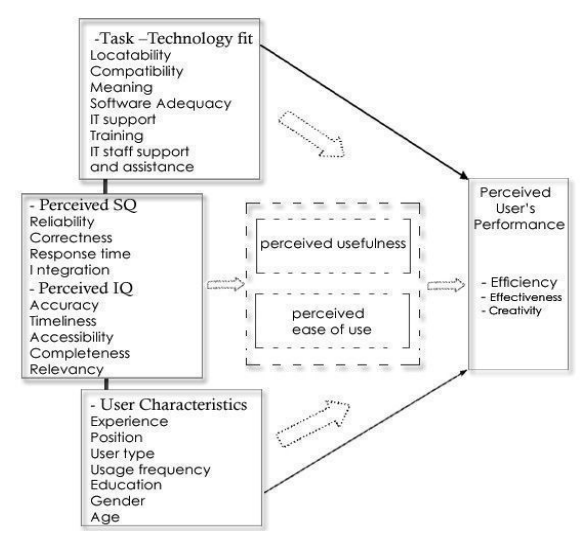

Figure 1. The study model

TAM, TTF and D \& M models have been tested in traditional IS environments, the new combined model was tested within an ERP systems environment. This environment was deemed appropriate as ERP systems are large scale systems 
which contains a range of applications that are used by various types of business organizations.

\section{METHODOLOGY}

This section describes the methodology used in the study and gives an overview of the pilot study and pretest procedures applied in order to validate the study model.

\section{A. PARTICIPANTS}

The respondents numbered 387 ERP users in total from various functional areas in different organizations. Data was collected from the ERP users by means of a written questionnaire. The questionnaire was synthesized after an extensive review of the IS and ERP literature. The questionnaire consisted of two parts, the first part involved demographic questions about the respondents and the frequency of ERP usage, while the second part involved questions about the factors including the fit between the system and task requirements and users' needs, System Quality (SQ), Information Quality (IQ), Perceived Usefulness (PU), Perceived Ease of Use (PEOU) and User Performance (UP). Both five and seven point Likert scales were used (see Appendix 1).

\section{B. PILOT STUDY AND PRE-TEST}

Although most of the factors used in the instrument were validated by prior research, the adopted questionnaire was evaluated through a focus group and tested in a pilot study to ensure content and construct validity and also to ensure appropriateness within the context of ERP environments.

The instrument then was distributed to 15 ERP users in three universities to evaluate ERP impacts on their performance. The data from those users was analyzed and the results of the analysis showed a high level of reliability. After ensuring appropriateness of the instrument the main study was conducted.

\section{RESULTS}

This section provides the main findings of the study and explains the results of the reliability and validity tests.

\section{A. MULTIVARIATE ASSUMPTION TESTING}

A preliminary analysis was performed to check for violations of the assumptions. The assumptions tested included outliers, linearity [25], homoscedasticity [38] and independent residuals [31].

The histogram plots showed some deviations from the normality for some variables, however, these deviations were not significant and they did not show any violations after they were tested using correlation tests.

The results presented in Table 1 show that all values of Durbin-Watson test came very close to 2 , meaning no presence of autocorrelation in the residuals. The results also showed that all values are less than one for Cook's distances and close to zero for the leverages thus confirming that no autocorrelation exists [9].

Table 1. Independence and outlier's analysis

\begin{tabular}{l|lllllll}
\hline Factors & $D V$ & $R$ & $R^{2}$ & $S . E$ & $D W$ & $C D$ & $C L$ \\
\hline TTF & UP & .63 & .40 & .88 & 2.09 & .034 & .027 \\
TTF & PU & .55 & .30 & .65 & 1.85 & .155 & .027 \\
TTF & PEOU & .64 & .41 & .68 & 1.79 & .093 & .027 \\
IQ & UP & .69 & .47 & .83 & 2.10 & .037 & .024 \\
IQ & PU & .67 & .46 & .57 & 1.76 & .035 & .024 \\
IQ & PEOU & .65 & .42 & .68 & 1.93 & .076 & .024 \\
SQ & UP & .79 & .62 & .70 & 2.02 & .097 & .034 \\
SQ & PU & .61 & .37 & .62 & 1.93 & .214 & .024 \\
SQ & PEOU & .66 & .44 & .67 & 1.74 & .019 & .034 \\
PU & UP & .75 & .57 & .75 & 2.10 & .155 & .035 \\
PEOU & UP & .65 & .43 & .86 & 1.93 & .027 & .017 \\
DW: Durbin-Watson, CD: Cook's Distance, CL: Centered \\
Leverage, DV: Dependent variables. \\
\hline \multicolumn{10}{c}{. }
\end{tabular}

\section{B. COLLINEARITY AND MULTICOLLINEARITY}

In practice, the most common level of cut-off points used for determining the presence of multicollinearity are tolerance values of less than .10, or Variable Inflation Factor (VIF) values of above 10 [31]. As illustrated in the Table 2, the tolerance values for all variables were above .10, and VIF values for each variable were less than 10 , therefore, the study did not violate the multicollinearity assumption [8].

\section{RELIABILITY}

The internal consistency reliability was assessed by calculating Cronbach's alpha values. An alpha of .70 or higher is normally considered satisfactory for most purposes [11], [30].

All individual factors, as well as the entire instrument have shown high levels of reliability. The Cronbach's alpha of the study instrument ranges from 0.84 for the usefulness to 0.97 for the user performance indicating high reliability. As summarized in Table 3 in the next section. 
Table 2. Cronbach's coefficient for the 52 item instrument and correlation of the study variables

\begin{tabular}{|l|l|l|l|l|l|l|l|l|l|l|}
\hline Constructs & Mean & \multirow{2}{*}{ S.D } & \multicolumn{3}{|l|}{ Inter correlation between variables } & \multicolumn{3}{l|}{ Collinearity } \\
\cline { 4 - 12 } & & & TTF & IQ & SQ & PU & PEOU & UP & Tolerance & VIF \\
\hline TTF & 4.95 & .96 & $\mathbf{( . 9 0 )}$ & & & & & & .434 & 2.304 \\
\hline IQ & 3.60 & .61 & .69 & $\mathbf{( . 8 7 )}$ & & & & & .327 & 3.057 \\
\hline SQ & 3.30 & .64 & .65 & .69 & $\mathbf{( 8 7 )}$ & & & & .389 & 2.57 \\
\hline PU & 3.90 & .78 & .54 & .59 & .61 & $\mathbf{( 8 4 )}$ & & & .504 & 1.983 \\
\hline PEOU & 3.30 & .89 & .62 & .63 & .67 & .54 & $\mathbf{( 8 9 )}$ & & .457 & 2.188 \\
\hline UP & 4.50 & 1.14 & .61 & .61 & .76 & .75 & .65 & $\mathbf{( 9 7 )}$ & & \\
\hline
\end{tabular}

TTF: Task technology fit, IQ: information quality, SQ: system quality, PU: perceived usefulness, PEOU: perceived ease of use, UP: user performance.

* Numbers in Parenthesis represent Cronbach's alpha. **Correlation is significant at the 0.01 level (2-tailed).

\section{VALIDITY}

Validity is the extent to which a construct measures what is supposed to measure reflecting how truthful the research results are, determining whether the research measures what was intended to measure [19].

Both Convergent and discriminant validity were used to confirm the appropriateness of the measurement obtained for the factors used in the study. The cut-off point used in this analysis was .3, as recommended by [37] and / or [31]. All correlations below this point were considered low. The analysis was conducted for each variable as shown in Table 3 below, followed by a discussion of the analysis results.

Table 3. Results of factor analysis*

\begin{tabular}{|c|c|c|c|c|c|c|c|}
\hline Factors/Items & Loading & Mean & SD & Factors/Items & Loading & Mean & SD \\
\hline \multicolumn{2}{|c|}{ Task technology fit } & 4.9 & .96 & Corr1 & .75 & 3.2 & .93 \\
\hline Loc1 & .74 & 5.3 & 1.39 & Corr2 & .60 & 3.3 & .92 \\
\hline Loc2 & .81 & 4.9 & 1.39 & \multicolumn{2}{|c|}{ Perceived usefulness } & 3.9 & .78 \\
\hline Com2 & .74 & 5.4 & 1.12 & PU1 & .69 & 3.9 & .83 \\
\hline Com3 & .75 & 5.3 & 1.14 & PU2 & .67 & 4.2 & 1.03 \\
\hline ITsub2 & .84 & 4.7 & 1.33 & PU3 & .76 & 3.7 & .92 \\
\hline ITsub3 & .85 & 4.8 & 1.31 & PU4 & .73 & 3.7 & .98 \\
\hline Ade1 & .84 & 4.8 & 1.34 & \multicolumn{2}{|c|}{ Perceived ease of use } & 3.3 & .89 \\
\hline Ade2 & .60 & 4.8 & 1.36 & PEOU1 & .72 & 3.2 & 1.00 \\
\hline Mea1 & .74 & 4.5 & 1.30 & PEOU2 & .85 & 3.2 & .97 \\
\hline Mea2 & .78 & 4.3 & 1.30 & PEOU3 & .89 & 3.4 & .98 \\
\hline \multicolumn{2}{|c|}{ Information quality } & 3.6 & .61 & & & & \\
\hline Accees1 & .71 & 3.5 & .90 & \multicolumn{2}{|c|}{ User performance } & 4.5 & 1.14 \\
\hline Access2 & .82 & 3.4 & .91 & Effici1 & .81 & 4.6 & 1.28 \\
\hline Complet1 & .50 & 3.4 & .88 & Effici2 & .77 & 4.9 & 1.34 \\
\hline Complet2 & .50 & 3.7 & .76 & Effici3 & .76 & 4.7 & 1.29 \\
\hline Tim1 & .53 & 3.6 & .86 & Effici4 & .76 & 4.6 & 1.32 \\
\hline Tim2 & .69 & 3.6 & .87 & Effici5 & .65 & 4.6 & 1.24 \\
\hline \multicolumn{2}{|l|}{ System quality } & 3.3 & .63 & Effici6 & .78 & 4.7 & 1.32 \\
\hline Integ1 & .77 & 3.1 & .85 & Effici7 & .74 & 4.8 & 1.35 \\
\hline Integ2 & .78 & 3.3 & .83 & Effici8 & .69 & 4.7 & 1.34 \\
\hline Integ3 & .58 & 3.2 & .99 & Effec1 & .715 & 4.5 & 1.38 \\
\hline Relia1 & .66 & 3.7 & .87 & Effec2 & .61 & 4.4 & 1.32 \\
\hline Relia2 & .83 & 3.6 & .79 & Effec3 & .60 & 4.7 & 1.30 \\
\hline Restime1 & .73 & 3.3 & .96 & Crea1 & .91 & 3.9 & 1.52 \\
\hline Restime2 & .74 & 3.2 & .94 & Crea1 & .83 & 3.7 & 1.57 \\
\hline
\end{tabular}

*Only loadings of 0.5 or above are shown 


\subsubsection{DISCRIMINANT VALIDITY}

We test discriminant validity for a construct using Cronbach's alpha. According to [4], [6] for a construct to be valid its Cronbach's alpha should be greater than its correlation with other constructs. As shown in Table 2 comparison of the correlations with the Cronbach's alphas indicated that this is true for all constructs and thus discriminant validity is satisfied [36].

\subsubsection{CONVERGENT VALIDITY}

All of the loadings of the constructs' items were higher than the cutoff criteria of 0.50 , with most of items above 0.70 , demonstrating high construct validity as shown in Table 3 . However, two items of the TTF construct (Com1 and ITsub1) did not meet

\subsection{MULTIPLE REGRESSION ANALYSIS}

A multiple regression analysis was performed to identify the significant contributions of each factor in explaining user performance with ERP systems. The results of the analysis, including significance levels, t-statistics and coefficients for each factor are summarized in Table 4. Three factors, PU, SQ and PEOU were found to be the best predictors of user performance explaining $61 \%$ of the variance in user performance. Furthermore, since PU had the strongest impacts on user performance further analysis was conducted to identify factors affecting PU. The analysis yielded a regression function with $\mathrm{R}^{2}=0.44$, based on all independent variables as summarized in Table 4.

Table 4. Multiple regressions analysis

\begin{tabular}{llllll}
\hline DV & $\mathrm{R}^{2}$ & IV & Beta & T & Sig \\
\hline UP & \multirow{2}{*}{0.61} & TTF & .076 & 1.411 & .058 \\
& & IQ & -.076 & -.250 & .077 \\
& & PU & .430 & 11.315 & $\underline{.000}$ \\
& & PEOU & .149 & 3.620 &. .000 \\
PU & \multirow{4}{*}{0.44} & TTF & .130 & 2.293 & .022 \\
& & SQ & .409 & 9.228 &. .000 \\
& & IQ & .328 & 5.877 & .000 \\
& & & .280 & 4.714 & .000 \\
\hline
\end{tabular}

\section{CONCLUSIONS}

The study provides insights to a potentially valuable tool for IS researchers and practitioners. The new combined model investigating the relationships between a set of factors including IQ, SQ, TTF and UP shows promise in enhancing the the cutoff criteria and thus were removed from any further analysis.

Similarly, Access 3 and Tim3, belonging to the SQ construct were dropped from any further analysis as they did not meet the cutoff criteria.

Accuracy and relevancy were not included in the factor analysis as they were measured by two items only. However, these sub-constructs show high correlation in terms of user performance, so they have been retained in the model.

In relations to UP, one item (Crea 3) was removed from the analysis because it had high loadings with other two sub-constructs and therefore creates ambiguity. To ensure that this item had no adverse effects, the reliability alpha was checked in both cases and showed no significant changes. Lastly, the PEOU and PU were tested. All items had high loadings $(<.60)$ in their perspective constructs suggesting high construct validity.

understanding of IS impacts in business organizations related to user performance.

Empirical findings demonstrated the significance of all of these factors but with different relative importance. The findings demonstrated that most factors in the proposed model have direct and/or indirect significant influence on user perceived performance suggesting therefore, that the model possesses the ability to explain the main impacts of these factors on ERP users.

The study shows that the most significant factor influencing user performance is Perceived Usefulness closely followed by system quality. These two factors provide a wider understanding of the factors that impact users when utilizing IS. The study provides a new foundation and draws attention for academic research related to information systems impacts and contributes to the improvement of user performance.

\section{REFERENCES}

[1] A. Abugabah and L. Sanzogni, "The impact of Information Systems on User Performance: A critical review and theoretical model" Proc. International Conference on Information Systems (ICIS), WASET, 2009, pp. 809-819.

[2] K. Amoako-Gyampah and A. Salam, "An extension of the technology acceptance model in an ERP implementation environment," Information and Management vol. 41, no. 6, 2004, pp. 731 - 745

[3] J. Bailey and S. Pearson, "Development of a Tool for Measuring and Analysing Computer User Satisfaction," Management Science, vol. 29, no. 5, 1983, pp. 530-545.

[4] A. Bajaj and S.R. Nidumolu, "A feedback model to understand information system usage," Information \& Management, vol. 33, no. 4, 1998, pp. 213-224.

[5] F. Calisir and F. Calisir, "The relation of interface usability characteristics, perceived usefulness and perceived ease of use to end -user satisfaction with 
enterprise resource planning systems," Computer in Human Behavior vol. 20, no. 505-515, 2004.

[6] D.T. Campbell and D.W. Fiske, "Convergent and discriminant validation by the multitrait multimethod matrix," Psychological Bulletin, vol. 56, 1959, pp. 81-105.

[7] L.-d. Chen, M. L. Gillenson \& D. L. Sherrell, (2002). Enticing online consumers: an extended technology acceptance perspective. Information \& Management, 39(8), 705-719.

[8] L. Cohen, L. Manion and K. Morrison, Research Methods in Education: a managerial approach Rutledgefalmer 2007.

[9] R.D. Cook and S. Weisberg, Residual and Influence in Regression, Chapman \& Hall, 1982.

[10] A. Crespo and R. Bosque, "The effect of innovativeness on the adoption of B2C e-commerce: A model based on the Theory of Planned Behaviour," Computers in Human Behavior, vol. 24, no. 6, 2008, pp. 2830-2847..

[11] J. Cronbach, "Coefficient alpha and the internal consistency of tests," Psychometrika vol. 16, 1951, pp. 297-334.

[12] F. Davis, "Perceived usefulness, perceived ease of use, and user acceptance of information technology," Management Information System Quarterly vol. 13, no. Sep, 1989, pp. 318-340.

[13] W. Delone and E. McLean, "Information systems success: the quest for the dependent variable," Information systems research vol. 3, no. 1, 1992, pp. 60-95.

[14] W. DeLone and E. McLean, "The DeLone McLean model of information system success: a tenyear update," Journal of Management Information Systems, vol. 19, no. 4, 2003, pp. 3-9.

[15] W. DeLone and E. McLean, "Measuring ECommerce Success: Applying the DeLone \& McLean Information Systems Success Model," International Journal of Electronic Commerce, vol. 9, no. 1, 2004, pp. 31-47.

[16] M. Dishaw and D. Strong, "Extending the Technology Acceptance Model with Task-Technology Fit Constructs," Information and Management vol. 36, no. 1, 1999, pp. 9-21.

[17] M.T. Dishaw and D.M. Strong, "Assessing software maintenance tool utilization using tasktechnology fit and fitness-for-use models," Journal of Software Maintenance, vol. 10, no. 3, 1998.

[18] T. Dishaw, D. Strong and B. Bandy, "Extending the task technology fit model with self efficacy constructs" pepper presented at Eighth Americas Conference on Information Systems, 2002, pp. 10211027.

[19] N. Golafshani, "Understanding Reliability and Validity in Qualitative Research "The Qualitative Report, vol. 8, no. 4, 2003, pp. 597-607

[20] D. Goodhue, "Development and measurement validity of a task-technology fit instrument for user evaluations of information systems," Decision Sciences, vol. 29, no. 1, 1998, pp. 105-138.

[21] D. Goodhue, B. Klein and S. March, "User evaluations of IS as surrogates for objective performance," Information \& Management, vol. 38, 2000, pp. 87-101.
[22] D. Goodhue and R. Thompson, "Tasktechnology fit and individual performance," $M I S$ Quarterly, vol. 19, no. 2, 1995, pp. 213-233.

[23] B. Hernández, J. Jiménez and M.J. Martín, "Extending the technology acceptance model to include the IT decision-maker: A study of business management software," Technovation, vol. 28, no. 3, 2008, pp. 112-121.

[24] W. Hong, J. Thong, W. Wong and K. Tam, "Determinants of user acceptance of digital libraries: an empirical examination of individual differences and system characteristics," Journal of Management Information Systems, vol. 18, no. 3, 2001, pp. 97-124.

[25] T. Keith, Multiple Regression and Beyond Allyn \& Bacon, 2005.

[26] T.G. Kim, J.H. Lee and R. Law, "An empirical examination of the acceptance behaviour of hotel front office systems: An extended technology acceptance model," Tourism Management, vol. 29, no. 3, 2008, pp. 500-513.

[27] I. Klopping and E. McKinney, "Extending the technology acceptance model and the task-technology fit model to consumer e-commerce," Information Technology, Learning, and Performance Journal, vol. 22 , no. 1, 2004, pp. 35 .

[28] B. Kositanurit, O. Ngwenyama and K. OseiBryson, "An exploration of factors that impact individual performance in an ERP environment: an analysis using multiple analytical techniques," European Journal of Information Systems, vol. 15, 2006, pp. 556-568.

[29] U. Nils, S. Stefan and R. Gerold, "Development and validation of a model for assessing the success of employee portals," Paper presented at the 17th European Conference on Information Systems, retrieved on 29/1/2010 from http://www.ecis.com.

[30] J. Nunnally, Psychometric theory McGraw-Hill, 1978.

[31] J. Pallant, SPSS Survival Manual: A step by step guide to data analysis using SPSS Allen \& Unwin, 2007.

[32] P.C. Palvia, "A model and instrument for measuring small business user satisfaction with information technology," Information \& Management, vol. 31 , no. 3,1996 , pp. 151-163.

[33] J. Roldán and A. Leal, "Executive information systems in Spain: a study of current practices and comparative analysis," Decision making support systems: achievements, trends and challenges for, IGI Publishing, 2003, pp. 287-304.

[34] Seddon, P., \& Kiew, M. (1994). A partial test and development of the DeLone and McLean model of IS success. Paper presented at the In DeGross, J Huff, L. Munro, M. Proceedings of the International Conference on Information Systems: Association for Information Systems, Atlanta.

[35] H. Shih, "Extended technology acceptance model of Internet utilization behavior," Information \& Management vol. 41, no. 6, 2004, pp. 719-729.

[36] R. Stone, D. Good and B. Eveleth, "The impact of information technology on individual and firm marketing performance," Behaviour \& Information Technology, vol. 26, no. 6, 2006, pp. $465-482$

[37] B. Tabachnick and L. Fidell, Using multivariate statistics Allyn \& Bacon, 2007. 
[38] O. Turel, A. Serenko and N. Bontis, "User acceptance of hedonic digital artifacts: A theory of consumption values perspective," Information \& Management, vol. 47, no. 1, 2010, pp. 53-59.

[39] V. Venkatesh and F. Davis, "A model of the antecedents of perceived ease of use: development and test.," Decision Science, vol. 27, no. 3, 1996, pp. 451481.

[40] V. Venkatesh and F. Davis, "A theoretical extension of the technology acceptance model: Four longitudinal field studies." Management Science, vol. 46, no. 2, 2000, pp. 186-205.

[41] N. Zhang, X. Guo and G. Chen, "Extended Information Technology Initial Acceptance Model and

\section{Appendix 1}

\begin{tabular}{|c|c|c|}
\hline \multicolumn{2}{|l|}{$\begin{array}{l}\text { Constructs } \\
\text { Task technology fit } * *\end{array}$} & \multirow[t]{6}{*}{$\begin{array}{l}\text { Source } \\
{[20],[22]}\end{array}$} \\
\hline Locatability & $\begin{array}{l}\text { 1. It is easy to determine what application is available and where to do my job. } \\
\text { 2. It is ease to locate the data in the ERP applications that I use. }\end{array}$ & \\
\hline Compatibility & $\begin{array}{l}\text { 1. ERP applications that I use are consistent with my tasks. } \\
\text { 2. ERP applications fit with my work aspects. }\end{array}$ & \\
\hline Meaning & $\begin{array}{l}\text { 1. The exact meaning of information obtained from the ERP, relating to my task, is easy to find out. } \\
\text { 2. The correct meaning of the information is obvious and clear on the ERP software }\end{array}$ & \\
\hline Adequacy & $\begin{array}{l}\text { 1. The ERP software that the university has meets my task requirements. } \\
\text { 2. The ERP software is adequate to handle my work processing needs. }\end{array}$ & \\
\hline IT support & $\begin{array}{l}\text { 1. I get the kind of quality computer-related training that I need. } \\
\text { 2. The IT people I deal with understand my work objectives. } \\
\text { 2. It is easy to get IT support and advice from IT people when I use ERP applications. }\end{array}$ & \\
\hline \multicolumn{2}{|c|}{ Information quality * } & \multirow[t]{6}{*}{ [13], [14] } \\
\hline Accuracy & 1. Our ERP system provides me with accurate information. & \\
\hline Relevancy & 1. Our ERP system provides relevant information. & \\
\hline Timeliness & $\begin{array}{l}\text { 1. Our ERP system provides me with the information I need in a timely manner. } \\
\text { 2. The information in our ERP system is timely and regularly updated. } \\
\text { 3. Getting information from our ERP system on time improves my work quality. }\end{array}$ & \\
\hline Completeness & $\begin{array}{l}\text { 1. I can find complete information when I need it in our ERP system. } \\
\text { 2. The information in our ERP system is sufficient to do my work. }\end{array}$ & \\
\hline Accessibility & $\begin{array}{l}\text { 1. The information in our ERP system is easily accessible. } \\
\text { 2. Information in our ERP system is easy retrievable. } \\
\text { 3. Convenience of information in our ERP system saves my time in my job. }\end{array}$ & \\
\hline $\begin{array}{r}\text { Perceived usefulness * } \\
1 \\
2 \\
3 \\
4\end{array}$ & $\begin{array}{l}\text { 1. Our ERP system is useful for my job performance. } \\
\text { 2. I can not accomplish my job without the ERP system. } \\
\text { 3. Our ERP system supports me in attaining my overall performance goals. } \\
\text { 4. Our ERP system makes it easer to do my job. }\end{array}$ & [5], [12] \\
\hline $\begin{array}{r}\text { Perceived ease of use* } \\
1 \\
2 \\
3\end{array}$ & $\begin{array}{l}\text { 1. Our ERP system is user friendly. } \\
\text { 2. It is easy to learn how to use our ERP system. } \\
\text { 3. I find the ERP system is easy to use. }\end{array}$ & {$[5],[12]$} \\
\hline \multicolumn{2}{|l|}{ System quality * } & \multirow[t]{5}{*}[13]{,$[14]$} \\
\hline Reliability & $\begin{array}{l}\text { 1. Our ERP system is reliable. } \\
\text { 2. Our ERP system has consistent information. }\end{array}$ & \\
\hline Correctness & $\begin{array}{l}\text { 1. I find it easy to correct the errors related to my work by using our ERP system. } \\
\text { 2. Our ERP system helps me reduce the errors in my job. }\end{array}$ & \\
\hline Response time & $\begin{array}{l}\text { 1. Our ERP system reacts and responds quickly when I enter the data. } \\
\text { 2. Our ERP system responds quickly to my inquiries. }\end{array}$ & \\
\hline Integration & $\begin{array}{l}\text { 1. Our ERP system allows for integration with other systems. } \\
\text { 2. Our ERP system effectively combines data from different areas of the university. } \\
\text { 3. Our ERP system is designed for all levels of user. }\end{array}$ & \\
\hline \multicolumn{2}{|l|}{ User performance** } & {$[2], \quad[21]$} \\
\hline Efficiency & $\begin{array}{l}\text { 1. I can accomplish my work quickly because of the ERP system quality. } \\
\text { 2. Our ERP system lets me do more work than was previously possible. } \\
\text { 3. Our ERP system has a positive impact on my productivity. } \\
\text { 4. Our ERP system reduces the time taken to accomplish my tasks. } \\
\text { 5. Our ERP system increases the cases I perform in my job. } \\
\text { 6. Using our ERP system in my job enables me to accomplish tasks more quickly. }\end{array}$ & [13] \\
\hline
\end{tabular}

Its Empirical Test," Systems Engineering - Theory \& Practice, vol. 27, no. 9, 2007, pp. 123-130.

\section{Corresponding author: Ahed Abugabah \\ Email: a.abugabah@griffith.edu.au $+61402336029$}


7. Overall, our ERP system improves my efficiency in my job.

8. Our ERP improves my performance quality.

Effectiveness $\quad$ 1. Our ERP helps me solve my job problems.

2. Our ERP reduces performance errors in my job.

2. Our ERP system enhances my effectiveness in my job.

Creativity

1. Our ERP helps me to create new ideas in my job.

2. Our ERP system enhances my creativity.

3. Overall our ERP system helps me achieve my job goals. 